\title{
Potential applications of lipid peroxidation products in renal transplantation
}

\author{
Omotayo O. Erejuwa*, Siti A. Sulaiman and Mohd S. Ab Wahab \\ *Correspondence: erejuwa@gmail.com \\ Department of Pharmacology, School of Medical Sciences, Universiti Sains Malaysia,16150 Kubang Kerian, Kelantan, Malaysia.
}

\begin{abstract}
There has been an increased prevalence of end-stage renal disease (ESRD) in the last decades. This can be attributed to high incidence of chronic diseases such as metabolic disorders, diabetes and hypertension. These diseases are often associated with ESRD, which requires regular dialysis and may later necessitate renal transplantation. The increased demand for renal transplantation has resulted in scarcity of donor kidneys leading to receipt of kidneys from extended criteria donors (ECDs) whose kidneys are susceptible to ischemic-injury. The levels of lipid peroxidation products, which are biomarkers of oxidative stress and damage, have been reported to be elevated in ischemic-injury. Therefore, transplantation of kidneys prone to ischemic-injury poses a great danger or high rate of failure in the recipients. The aim of this mini review is to highlight the potential usefulness or application of lipid peroxidation products in screening donor kidneys for renal transplantation. As a result of machine perfusion (MP), it is now possible to determine certain biomarkers such as lipid peroxidation products in the perfusate which reveal kidneys that have undergone severe ischemic and/or oxidative damage. This will help in screening or identification of kidneys that are unfit for transplantation. Besides, lipid peroxidation products can also be used to monitor or evaluate patient's post-transplant recovery. Thus, measurement of lipid peroxidation products may help to reduce post-transplant failure and improve the quality of life of recipients.

Keywords: Lipid peroxidation products, kidney, extended criteria donors, machine perfusion, renal transplantation
\end{abstract}

\section{Introduction}

There has been an increased demand for renal transplantation in the last decades. This can be attributed to increasing number of patients with EDRD which may result from chronic diseases such as metabolic disorders, diabetes mellitus and hypertension [1]. Unfortunately, there are only limited kidney donors. This limited supply of donor kidneys has resulted in less strictness with regards to sources of kidney donors [2]. Thus, donor kidneys from diverse sources including the ECDs are received and transplanted [3]. However, reports indicate that kidneys sourced from ECDs are characterized by post-transplant complications such as acute rejection episodes, primary nonfunction, greater rate of delayed graft function (DGF) and greater frequency of graft failure [4]. The cold-storage and machine perfusion (MP) are two commonly employed techniques for the preservation of kidneys before transplantation [5]. Recent findings indicate that MP of donor kidneys is associated with some advantages such as reduced rates of DGF and better graft survival $[6,7]$. The use of MP allows certain important biomarkers in the perfusate to be evaluated and thereby provides information on the potential failure or success of post-kidney transplantation. One of such biomarkers is lipid peroxidation products. Lipid peroxidation products are biomarkers of oxidative stress, resulting from reactive oxygen species (ROS)attack of polyunsaturated fatty acids (PUFAs). They are reactive aldehydes which are injurious to cellular components such as proteins and deoxyribonucleic acid (DNA) [8]. These aldehydes which include 4-hydroxynonenal (HNE), malondialdehyde (MDA), isoprostanes (IsoPs), neuroprostanes (neuroPs), isofurans and acrolein are associated with several chronic diseases such as diabetes mellitus, hypertension and Alzheimer's disease [9-11] and other pathological states such as ischemia [12]. The aim of this mini review is to posit and highlight the potential applications of lipid peroxidation products in screening donor kidneys for renal transplantation.

\section{Potential applications of lipid peroxidation products in renal transplantation}

The suitability of kidneys for transplantation can now be determined by quantifying the levels of certain biomarkers including lipid peroxidation products in the perfusate. Transplanted kidneys are vulnerable to DGF-a form of acute kidney injury that immediately followed transplantation [13]. Among the common causes of DGF include ischemic kidney injuries in the donors [14]. Ischemia in kidney is associated with increased lipid peroxidation products $[15,16]$. In fact, lipid peroxidation biomarkers, MDA and HNE, are considered key biomarkers of ischemic kidney [17] and thus could be used in the detection of renal ischemic damage. Similarly, other lipid peroxidation products such as 8-isoprostane have been shown to be a potential reliable biomarker to predict renal ischemic injury during kidney transplant [18]. Lipid peroxidation products can also be used to monitor the response and progress of patient's recovery after kidney transplant. In renal transplant 
patients with chronic biopsy-proven rejection, the level of lipid peroxidation products is higher than in patients with stable function [19]. On the other hand, the levels of lipid peroxidation products such as MDA and F2-IsoPs have been found to be significantly lower and remain lower for months after renal transplantation $[19,20]$. Similarly, on postoperative day 5 , higher serum creatinine concentrations and lower estimated glomerular filtration rate (eGFR) have been reported in high lipid peroxidation (LPO) group than in the low LPO group [21]. After 1 year, however, the serum creatinine concentrations and eGFR were similar between the groups [21].

Recently, it was reported that lipid peroxidation products and the activity of the enzyme (glutathione S-transferase) responsible for their elimination were considerably elevated at the end of MP [22]. The study also found that DGF after transplantation could be predicted by the levels of lipid peroxidation markers [22]. Considering the role of lipid peroxidation in the pathobiology of ischemic injury, some researchers have also attempted to use free radical scavengers or antioxidants to minimize post-transplant complications and the results are encouraging [23-25]. Although data are still limited, based on these few findings, it could be suggested that regular assessment of lipid peroxidation products in the perfusate of donor kidneys may help to detect those kidneys which have undergone severe oxidative damage. Such oxidatively-damaged kidneys need to be rejected. In other words, the clinical decision on the suitability of donor kidneys for transplantation could be arrived at partly by quantifying lipid peroxidation products.

\section{Conclusion}

The problem of kidney scarcity is a global phenomenon leading to an increased gap between supply of and demand for existing kidneys. This, therefore, necessitates the acceptance of kidneys from ECDs whose kidneys are highly prone to ischemic-injury induced DGF. The determination of lipid peroxidation products might be useful in renal transplantation in many ways. With the aid of MP, it becomes possible to measure lipid peroxidation products which reveal kidneys that have undergone severe ischemic and/or oxidative damage. For clinical decision making process, such data can be valuable in excluding those kidneys from being transplanted. This will help to ensure only donor kidneys that have better viability and quality are transplanted. Moreover, patient's post-transplant recovery can be assessed via lipid peroxidation products. There is also a good prospect for the use of free radical scavengers or antioxidants, especially with early intervention, to minimize or delay post-transplant complications such as DGF resulting from oxidative stressinduced ischemic damage. Thus, measurement of lipid peroxidation products will not only be cost-effective but also help to minimize post-transplant complications and the likelihood of kidney transplant failure. In view of the limited data, there is no doubt that the potential application of lipid peroxidation products in renal transplantation is an area that requires an attention and further studies. It has a potential that may invariably contribute to improved post-transplant survival as well as better quality of life of recipients. These lipid peroxidation products may also be relevant in other organ transplantations.

\section{List of abbreviations}

ESRD: end-stage renal disease

ECD: extended criteria donors

MP: machine perfusion

DGF: delayed graft function

ROS: reactive oxygen species

PUFAs: polyunsaturated fatty acids

dna: deoxyribonucleic acid

HNE: 4-hydroxynonenal

MDA: malondialdehyde

IsoPs: isoprostanes

NeuroPs: neuroprostanes

eGFR: estimated glomerular filtration rate

LPO: lipid peroxidation

\section{Competing interests}

The authors declare that they have no competing interests.

\section{Authors' contributions}

\begin{tabular}{|l|c|c|c|}
\hline Authors' contributions & OOE & SAS & MSW \\
\hline Research concept and design & $\checkmark$ & -- & -- \\
\hline Collection and/or assembly of data & $\checkmark$ & -- & -- \\
\hline Data analysis and interpretation & $\checkmark$ & -- & -- \\
\hline Writing the article & $\checkmark$ & -- & -- \\
\hline Critical revision of the article & $\checkmark$ & $\checkmark$ & $\checkmark$ \\
\hline Final approval of article & $\checkmark$ & $\checkmark$ & $\checkmark$ \\
\hline
\end{tabular}

Publication history

Editor: Elsie Maria Muller, University of Cape Town, South Africa. EIC: Stephen C Strom, Karolinska Institutet, Sweden.

Received: 27-Aug-2013 Accepted: 10-Oct-2013

Published: $25-$ Oct-2013

\section{References}

1. Arulkumaran N, Annear NM and Singer M. Patients with end-stage renal disease admitted to the intensive care unit: systematic review. $\mathrm{Br} J$ Anaesth. 2013; 110:13-20. | Article | PubMed

2. Tsoulfas G. Commentary on: Lipid peroxidation in machine perfusion of older donor kidneys. J Surg Res. 2012 [Epub ahead of print]. | Article | PubMed

3. Singh SK and Kim SJ. Does expanded criteria donor status modify the outcomes of kidney transplantation from donors after cardiac death? Am J Transplant. 2013; 13:329-36. | Article | PubMed

4. Barba J, Zudaire JJ, Robles JE, Rosell D, Berian JM and Pascual I. Complications of kidney transplantation with grafts from expanded criteria donors. World J Urol. 2013; 31:893-900. | Article | PubMed

5. Yuan X, Theruvath AJ, Ge X, Floerchinger B, Jurisch A, Garcia-Cardena $G$ and Tullius SG. Machine perfusion or cold storage in organ transplantation: indication, mechanisms, and future perspectives. Transpl Int. 2010; 23:561-70. | Article | PubMed

6. Cannon RM, Brock GN, Garrison RN, Smith JW, Marvin MR and Franklin GA. To pump or not to pump: a comparison of machine perfusion vs cold storage for deceased donor kidney transplantation. J Am Coll Surg. 2013; 216:625-33; discussion 633-4. | Article | PubMed 
7. Moers C, Pirenne J, Paul A and Ploeg RJ. Machine perfusion or cold storage in deceased-donor kidney transplantation. N Engl J Med. 2012; 366:770-1. | Article | PubMed

8. Fukuda M, Kanou F, Shimada N, Sawabe M, Saito Y, Murayama $\mathrm{S}$, Hashimoto $\mathrm{M}$, Maruyama $\mathrm{N}$ and Ishigami $\mathrm{A}$. Elevated levels of 4-hydroxynonenal-histidine Michael adduct in the hippocampi of patients with Alzheimer's disease. Biomed Res. 2009; 30:227-33. | Article | PubMed

9. Butterfield DA, Bader Lange ML and Sultana R. Involvements of the lipid peroxidation product, $\mathrm{HNE}$, in the pathogenesis and progression of Alzheimer's disease. Biochim Biophys Acta. 2010; 1801:924-9. | Article | PubMed Abstract | PubMed Full Text

10. Erejuwa OO, Sulaiman SA, Ab Wahab MS, Sirajudeen KN, Salleh S and Gurtu S. Honey supplementation in spontaneously hypertensive rats elicits antihypertensive effect via amelioration of renal oxidative stress. Oxid Med Cell Longev. 2012; 2012:374037. | Article | PubMed Abstract I PubMed Full Text

11. Erejuwa OO, Sulaiman SA, Wahab MS, Salam SK, Salleh MS and Gurtu S. Comparison of antioxidant effects of honey, glibenclamide, metformin, and their combinations in the kidneys of streptozotocin-induced diabetic rats. Int. J. Mol. Sci 2011; 12: 829-43. | Article

12. Nagakannan P, Shivasharan BD, Thippeswamy BS and Veerapur VP. Effect of tramadol on behavioral alterations and lipid peroxidation after transient forebrain ischemia in rats. Toxicol Mech Methods. 2012; 22:674-8. | Article | PubMed

13. Butala NM, Reese PP, Doshi MD and Parikh CR. Is delayed graft function causally associated with long-term outcomes after kidney transplantation? Instrumental variable analysis. Transplantation. 2013; 95:1008-14. | Article | PubMed

14. Sharif $A$ and Borrows R. Delayed graft function after kidney transplantation: the clinical perspective. Am J Kidney Dis. 2013; 62:1508. | Article | PubMed

15. Yun Y, Duan WG, Chen P, Wu HX, Shen ZQ, Qian ZY and Wang DH. Ischemic postconditioning modified renal oxidative stress and lipid peroxidation caused by ischemic reperfusion injury in rats. Transplant Proc. 2009; 41:3597-602. I Article I PubMed

16. Hosseini F, Naseri MK, Badavi M, Ghaffari MA, Shahbazian H and Rashidi I. Effect of beta carotene on lipid peroxidation and antioxidant status following renal ischemia/reperfusion injury in rat. Scand J Clin Lab Invest. 2010; 70:259-63. | Article | PubMed

17. Eschwege P, Paradis V, Conti M, Holstege A, Richet F, Deteve J, Menager $P$, Legrand A, Jardin A, Bedossa $P$ and Benoit $G$. In situ detection of lipid peroxidation by-products as markers of renal ischemia injuries in rat kidneys. J Urol. 1999; 162:553-7. | Article | PubMed

18. Waller HL, Harper SJ, Hosgood SA, Bagul A, Yang B, Kay MD, Kaushik $\mathrm{M}$ and Nicholson ML. Biomarkers of oxidative damage to predict ischaemia-reperfusion injury in an isolated organ perfusion model of the transplanted kidney. Free Radic Res. 2006; 40:1218-25. | Article | PubMed

19. Simic-Ogrizovic S, Simic T, Reljic Z, Markovic S, Blagojevic R, Radivojevic $D$, Lezaic V, Djukanovic L and Mimic-Oka J. Markers of oxidative stress after renal transplantation. Transpl Int. 1998; 11 Suppl 1:S125-9. | Article | PubMed

20. Simmons EM, Langone A, Sezer MT, Vella JP, Recupero P, Morrow JD, Ikizler TA and Himmelfarb J. Effect of renal transplantation on biomarkers of inflammation and oxidative stress in end-stage renal disease patients. Transplantation. 2005; 79:914-9. | Article I PubMed

21. Joo DJ, Huh KH, Cho Y, Jeong JH, Kim JY, Ha H and Kim YS. Change in serum lipid peroxide as an oxidative stress marker and its effects on kidney function after successful kidney transplantation. Transplant Proc. 2010; 42:729-32. | Article | PubMed

22. Nagelschmidt M, Minor T, Gallinat A, Moers C, Jochmans I, Pirenne J, Ploeg RJ, Paul A and Treckmann J. Lipid peroxidation products in machine perfusion of older donor kidneys. J Surg Res. 2013; 180:33742. | Article | PubMed

23. Land W, Schneeberger H, Schleibner S, Illner WD, Abendroth D, Rutili G, Arfors $\mathrm{KE}$ and Messmer $\mathrm{K}$. The beneficial effect of human recombinant superoxide dismutase on acute and chronic rejection events in recipients of cadaveric renal transplants. Transplantation. 1994; 57:2117. | Article | PubMed

24. Mallet RT, Sun J, Knott EM, Sharma AB and Olivencia-Yurvati AH. Metabolic cardioprotection by pyruvate: recent progress. Exp Biol Med (Maywood). 2005; 230:435-43. | PubMed

25. Treska V, Kobr J, Hasman D, Racek J, Trefil L, Reischig T, Hes O, Kuntscher $\mathrm{V}$, Molacek J and Treska I. Ischemia-reperfusion injury in kidney transplantation from non-heart-beating donor--do antioxidants or antiinflammatory drugs play any role? Bratisl Lek Listy. 2009; 110:133-6. I PubMed

\section{Citation:}

Erejuwa OO, Sulaiman SA and Ab Wahab MS. Potential applications of lipid peroxidation products in renal transplantation. Transplant Technol. 2013; 1:3. http://dx.doi.org/10.7243/2053-6623-1-3 